\title{
Effect of Ethnophysics - Based Instruction on Students' Academic Performance and Attitude Towards Density, Forces and Heat Transfer in College Physics: A Case of Mufulira College of Education
}

\author{
Ephraim Chongo $^{1^{*}} \quad$ Gurudas Trivikram Baliga $^{2}$ \\ 1. Natural Sciences Department, Mufulira College of Education, P. O Box 40400, Mufulira, Zambia \\ 2. School of Mathematics and Natural Sciences, Copperbelt University, P. O Box 21692, Kitwe, Zambia
}

\begin{abstract}
This study investigated the effect of Ethnophysics - Based Instruction on students' academic performance and attitude towards Density, Forces and Heat Transfer at Mufulira College of Education, Mufulira District, Copperbelt Province of Zambia. The study employed a quasi -experimental: pre-test - post-test control group design on 156 purposively sampled students. The research questions were answered using descriptive statistics. The hypotheses on both academic performance and attitude were tested using two sample t-test statistic, at 0.05 level of significance. The study found that the experimental group performed better than the control group $t_{(154)}$ $=6.06 ; \mathrm{p}<0.05$. It also found that Ethnophysics - Based Instruction which was used to teach the experimental group enhanced the attitude better than the conventional method which was used to teach the control group $t_{(154)}$ $=7.49 ; \mathrm{p}<0.05$. Lastly the study revealed that Ethnophysics - Based Instruction is a gender friendly teaching approach when teaching Density, Forces and Heat Transfer to students $t_{(69)}=-0.68 ; \mathrm{p}>0.05$. The study concludes that this instructional approach is a viable innovation for the enhancement of students' academic performance and attitude towards the mentioned three topics and that it is not gender biased. The study recommends that lecturers should use Ethnophysics - Based-Instructions in their teaching. Physics courses in pre-service teacher training should be taught using Ethnophysics - Based Instruction. At the in-service level, seminars and workshops should be organized to educate practicing lecturers on how to use Ethnophysics - Based Instruction in teaching.
\end{abstract}

Keywords: ethnophysics, attitude, home practices, ethnophysics - based instruction

DOI: $10.7176 / \mathrm{JEP} / 10-20-03$

Publication date:July $31^{\text {st }} 2019$

\section{Introduction}

This study focused on Physics at college level. Physics is a branch of science that studies the natural symptoms and interactions (Navika and Fajar, 2016) whose role in society cannot be overemphasized. This subject has attracted a lot of research because it has from time immemorial to date recorded poorest enrolments, it has suffered negative attitude from students and it has been the poorly performed subject among the sciences worldwide, in Africa and in Zambia (Kola, 2014; Guido, 2013; Maguswi, 2011) respectively. These researchers have found several reasons such as learners' failure to interact meaningfully with alien, imported and imposed learning materials and environments, learners' negative attitude towards Physics, and largely, the ineffective instructional strategies employed by educators being responsible for the persistent poor performance in Physics at all levels. Additionally, the Zambia's Seventh National Development Plan 2017 - 2021 indicates that one of the major challenges the education system faces in Zambia is low quality of education as evidenced by low performance.

\subsection{Statement of the Problem}

The performance in Physics and attitude towards Physics at Mufulira College of Education are no better than elsewhere because Physics at diploma level recorded highest numbers of candidates failing. Table 1 shows the comparison of failure rate among Biology, Chemistry and Physics for the years 2012, 2015 and 2018. 
Table 1: Number of candidates who failed Physics compared to those who failed Biology and Chemistry at diploma level.

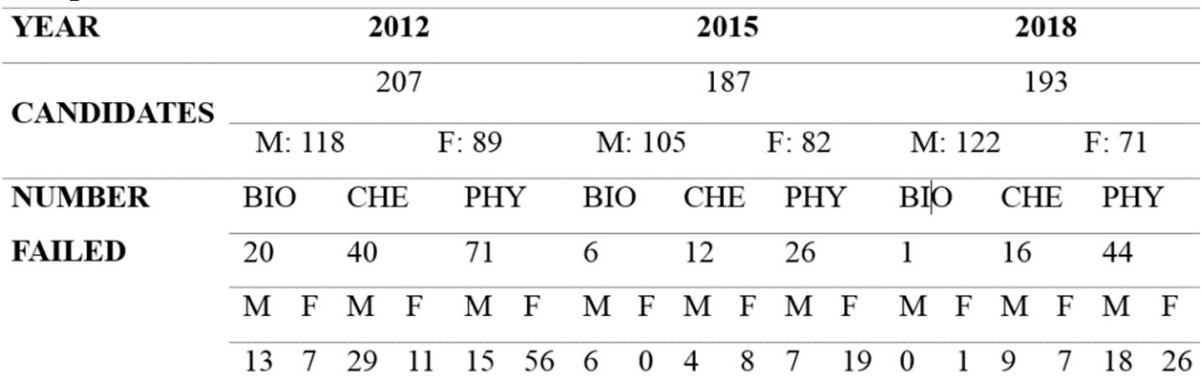

Source: (College Secretariat).

Key for Table $1: \mathrm{M}=$ Male, $\mathrm{F}=$ Female, $\mathrm{BIO}=$ Biology, $\mathrm{CHE}=$ Chemistry, $\mathrm{PHY}=$ Physics.

Kola (2014), Abonyi et al (2014) and Maguswi (2011) cited in Kola (2014) note that Physics is generally an underachieved course everywhere from time immemorial. They have indicated that Europe has a relative better standing while Africa is the poorest performing continent in Physics. They have reported that there is low enrolment in physics and that girls' performance is below that of boys'. Adesoji (2008) and Guido (2013) have established that a significant relationship exists between attitude and method of instruction and also between attitude and performance and it is possible to predict performance from attitude scores. Hence, performance and attitude can be attributed to the teaching approach used. Simply put, poor performance, negative attitude and low enrolment levels are a reflection of how effective/defective teaching methods used are in the teaching of Physics at all levels of learning. Students do not learn because there is a gap in today's education system between how students live and what they learn and how they learn (Halubova, 2008). The Teacher Education Diploma Syllabus for Physics in Zambia lacks a method which considers learners' culture as prior knowledge for learning school physics as seen from the list of suggested teaching methods. To this effect, it is wise to recognize and implement counsel given in Ministry of General Education Bulletin (2017) that if a learner cannot learn the way we teach, maybe we should teach the way they learn. It can therefore be said that poor performance in Physics is mainly attributed to instructional approaches employed in teaching Physics to learners. It is very clear that EthnophysicsBased Instruction has no recognition and place in both documents guiding Teacher Education in Zambia and in classroom practice as a classroom instructional method for the purpose of creating fertile ground for good performance and positive attitude formation but as a compensatory measure.

The researcher did not come across literature in Zambia on the use of Ethnophysics-Based Instruction in formal Physics teaching to improve performance and positive attitude formation towards Physics except Musonda (2013) who studied ethnophysics in terms of energy content in indigenous trees as a source of energy in Kafironda forest in Mufulira District, Zambia.

The repercussion of not changing physics teaching approach is that Physics teachers will be difficult to find and so teacher - pupil ratios in schools and colleges of education will remain unpleasant. All Physics dependent advancements will remain backwards as the economy of Zambia continues dwindling burying hopes for realization of benefits of national development plans for Zambia as physics is at the heart of technology which in turn is the driver of the economy and development.

It is against this background that the researcher examined the effect of Ethnophysics-Based Instruction on students' academic performance and attitude towards density, forces and heat transfer in college Physics.

\subsection{Scope of the study}

This study was designed for students at Mufulira College of Education pursuing a diploma in science. It focused on examining the effect of Ethnophysics - Based Instruction on their academic performance and attitude towards Density, Forces and Heat Transfer in College Physics. It further sought to establish its effect on students' attitude basing on gender. The following Research Questions and Null Hypotheses were formulated to guide the study:

1. What is the statistical difference between the academic performance mean scores of students taught Density, Forces and Heat Transfer using Ethnophysics-Based Instruction and those taught using conventional method?

2. What is the statistical difference in mean attitude scores between students taught Density, Forces and Heat Transfer using Ethnophysics-Based Instruction and those taught using conventional method?

3. What is the statistical difference in mean attitude scores between male and female students taught Density, Forces and Heat Transfer using Ethnophysics-Based Instruction?

Ho1: There is no statistically significant difference in academic performance mean scores between students taught Density, Forces and Heat Transfer using Ethnophysics-Based Instruction and those taught using conventional method. 
Ho2: There is no statistically significant difference in the mean attitude scores between students taught Density, Forces and Heat Transfer using Ethnophysics-Based Instruction and those taught using conventional method.

$\mathbf{H}_{\mathbf{0} 3}$ : There is no statistically significant difference in mean attitude scores between male and female students taught Density, Forces and Heat Transfer using Ethnophysics-Based Instruction.

\subsection{Theoretical and methodological framework}

This study is rooted in both Haskell's (2001) transfer of learning and Ausubel's (1972) subsumption theory of meaningful learning. Haskell stated that all learning is transfer of learning, which is to say learning takes place in analogue. Learners can only learn school Physics well and with minimal barriers if their indigenous knowledge is part of school physics instruction. In a similar manner, Ugwu and Diovu (2016) submitted that Ausubel emphasized the role of the existing cognitive structure or advance organisers in subsuming newly introduced concepts to be learnt. According to subsumption theory of meaningful learning, learning occurs when there is interaction between the learner's appropriate knowledge that already exists in the cognitive structure and the new material to be learnt which undergo change and growth. Here ethno-physics knowledge, artefacts and practices form the learners' knowledge structure while school physics is the new material to be learned bridged by Ethnophysics - Based Instruction manifested through academic performance and attitude.

The study adopted the critical (emancipatory and transformative) paradigm in instrumentation, data collection and data analysis which allows the use of mixed methods of quantitative and qualitative research. This paradigm aims at destroying myths and empower people to change society radically with a steady focus on critical praxis using multiple realties shaped by social, political, cultural, economic, race, ethnic, gender and disability values where all science must begin with a value position; however, some positions are right, some are wrong.

\section{Literature Review}

Ethnophysics is mostly found in African/non-European literature because it is the African/indigenous Knowledge which has Physics concepts and principles which Abonyi, (1999) cited in Nwosu and Ibe, (2017) define it as materials, ideas and beliefs from the African environment and technology while to Heckenberger (2005), ethnophysics refers to indigenous systems of knowledge that incorporate elements of what, in Western societies, are called mathematics, engineering, astronomy and calendric. Ethnophysics describes the peoples, environment and cultures (Lawrence, 2017). Hinging physics instruction on ethnophysics and as a tool, gives Ethnophysics - Based Instruction an approached which was used in this study.

Shumba (2017) observes that the curriculum is not adequately contextualised and largely lacks inclusivity with respect to local examples and cultures that may inform pedagogy. Other researchers with similar observation are: (Halubova, 2008; Guido, 2013; Ugwu \& Diovu, 2016; Nwosu and Ibe, 2017 and Abonyi et al, 2014).

Adams (1983) noted that nobody has monopoly of truth adding that there is no correct way of knowing; there are ways of knowing. As early as 1938 Raum (1938:4-5) as cited in Naidoo (2010), education cannot be truly effective until it is intelligently based on the indigenous culture and living interests. Learning can be more effective provided it starts from cultural or cognitive experiences of students (Masingila, 1993). Until definitions of science become more harmonious with personal values, physics will continue to be unappealing to many students (Michie, 1999:8). If it remains unappealing to many students, their performance in physics will continue to be poor. And Malcolm (2001:10) said, the science (Physics) of the curriculum should serve to support needs of all students ranging from those who see themselves as potential scientists to those who would prefer to remain in the rural villages, close to traditional belief systems. In view of all the above recognition of culture in Physics teaching and learning, Naidoo (2010) puts it that since schools exist as agencies for the transfer of the culture of the society from one generation to the next, a good deal of what is taught and how it is taught in school physics should be decided by reference to the culture of that society. Therefore, the curriculum should acknowledge the role of indigenous knowledge in learning school physics as informed by these research works. According to Abonyi (2014), any assumption that an African learner can easily be adjusted to a drastic change without creating a suitable link is bound to fail. For this learner to adapt to a new field of knowledge, the gap between him - his culture and the new field of knowledge has to be bridged.

Several researchers have integrated ethnophysics in physics instruction and none of them has reported negative effects the integration in academic performance and attitude. Students had better academic performance and attitude than their counterparts who learnt same concepts using other teaching approaches (Nashon and Anderson 2013; Savelsbergh's et al, 2016; Nwosu \& Ibe, 2017; Achor, Imoko, \& Uloko, 2009 and Peni, 2015).

\section{Methodology and Procedures}

The study employed a quasi-experimental design of non-equivalent groups. More precisely, a pre-test - post-test control group design in which mixed methods of qualitative and quantitative approaches in data collection and 
analysis were used in line with the critical paradigm used for this study. This design was adopted because the college had two classes of first year diploma Physics students where the selected topics were taught. The classes were Class A and Class B. Purposive sampling of the classes was used in this study to draw research participants. This helped in minimizing treatment diffusion as members of these classes were new to one another. Additionally, class A was a morning class while class B was an afternoon class. Random assignment was used to assign the two classes to experimental and control groups by toss of a coin. The population of Mufulira College of Education was 1718 students. The target population in this study was 358 Physics students. The sample for this study was 156 students: 71students from class A (experimental group) taught Density, Forces and Heat Transfer using EBI (Treatment) and 85students from class B (control group) taught the same topics using Conventional Method. The purposive choice of Density, Forces and Heat Transfer for this study came as noted that these topics are threshold concepts in Physics and that they are reported by both learners and teachers that they are difficult (Kiptum, 2015; Pen, 2015 and Ogunkola \& Samuel 2011). Additionally, they have been found to be commonly practiced in many Zambian societies but with a lot of misconceptions such as size is proportional to density, force taken as power and that cold moves from one point to another.

Two instruments were used to collect data: Achievement Test and Attitude Questionnaire. All the data were analysed quantitatively as permitted by Harry and Deborah (2012) that Likert Type items can be analysed using two - sample $\mathrm{t}$ - test.

All three research questions were answered by descriptive statistics of the mean and standard deviation. Similarly, all three null hypotheses were tested using two sample t-test statistic on SPSS at alpha $=0.05$. This is because Gail and Anthony (2013) have permitted that parametric tests tend to give the right answers even when statistical assumptions such as normality are violated even to an extreme degree.

\section{Results}

Two types of data were collected:

1. Pre-test and post-test of students' scores in ATs on density, forces and heat transfer.

2. Pre-test and post-test scores of students' attitude towards density, forces and heat transfer in college physics.

Research Question 1: What is the statistical difference between the academic performance mean scores of students taught Density, Forces and Heat Transfer using Ethnophysics-Based Instruction and those taught using conventional method?

Table 7 and table 8 show means, standard deviations and the standard error means in both pre-test and post-test. Table 2: Pre - Test Comparison of means and standard deviations between Experimental and Control groups in Achievement Test $(n=156)$

\section{GROUP N Mean Std. Deviation Std. Error Mean}

\begin{tabular}{llcccc}
\hline & Experimental & 71 & 11.82 & 3.21 & 0.38 \\
$\begin{array}{l}\text { Pre-test scores } \\
\text { on Achievement } \\
\text { Test }\end{array}$ & & & & & \\
& Control & 85 & 12.73 & 3.17 & 0.34 \\
\hline
\end{tabular}

Table 3: Post-Test Comparison of means and standard deviations between Experimental and Control groups in Achievement Test $(\mathbf{n}=\mathbf{1 5 6})$

\section{GROUP N Mean Std. Deviation Std. Error Mean}

\begin{tabular}{llcccc}
\hline & Experimental & 71 & 21.42 & 3.53 & 0.42 \\
$\begin{array}{l}\text { Post-test scores } \\
\text { on Achievement } \\
\text { Test }\end{array}$ & Control & 85 & 18.14 & 3.23 & 0.35 \\
\hline
\end{tabular}

Results of table 7 and table 8 show means of the pre-test and post-test of the experimental group and the control group for this study. The experimental group's means were 11.82 and 21.42 in pre-test and post-test 
respectively. The gain was 9.60. Its standard deviations in both pre-test and post-test stood at 3.21 and 3.53 respectively. The control group recorded 12.73 as mean score in pre-test and 18.14 mean score in post-test, giving a gain of 5.41. The control group's standard deviations were 3.17 and 3.22. These results show that the experimental group was outperformed by the control group by 0.91 in the pre-test. However, the control group was outperformed in the post-test by 3.28. The 9.60 gain in the experimental group against 5.41 gain in the control group could indicate the potential which Ethnophysics - Based Instruction has in improving academic achievement. The 3.28 mean difference in the post-test against 0.91 mean difference in the pre-test reveals that Ethnophysics - Based Instruction (treatment) had a greater positive effect on enhancing students' academic performance.

Research Question 2: What is the statistical difference in mean attitude scores between students taught Density, Forces and Heat Transfer using Ethnophysics-Based Instruction and those taught using conventional method?

Table 4: Post-Test Comparison of means and standard deviations between Experimental and Control groups in Achievement Test $(\mathbf{n}=\mathbf{1 5 6})$

\section{$\begin{array}{llll}\text { GROUP } \quad \text { N } \quad \text { Mean } & \text { Std. Deviation } \quad \text { Std. Error Mean }\end{array}$}

$\begin{array}{lllll}\text { Experimental } & 71 & 24.80 & 4.93 & 0.59\end{array}$

\section{Pre-test scores} on Attitude

$\begin{array}{lllll}\text { Control } & 85 & 25.14 & 4.33 & 0.47\end{array}$

Table 5: Post-Test Comparison of means and standard deviations between Experimental and Control groups in Attitude scores $(n=156)$.

\section{GROUP N Mean Std. Deviation Std. Error Mean}

$\begin{array}{lllll}\text { Experimental } & 71 & 40.48 & 4.87 & 0.51\end{array}$

\section{Post-test scores on Attitude}

$\begin{array}{lllll}\text { Control } & 85 & 34.96 & 4.81 & 0.52\end{array}$

Table 9 and table 10 show that the experimental group recorded mean attitudes of students for both pre-test and post-test as $24.80(\mathrm{SD}=4.93)$ and $40.48(\mathrm{SD}=4.29)$ producing a gain of 15.68 while control group recoded $25.14(\mathrm{SD}=4.33)$ and $34.96(\mathrm{SD}=4.81)$ with 9.82 as gain respectively. In the pre-test, the groups' means differed by 0.34 in favour of the control group. On the contrary, the groups' means were separated by 5.52 with the experimental group having a higher positive attitude towards Density, Forces and Heat Transfer in college Physics in the post-test. Despite the experimental group having a lower attitude mean score in the pre-test, it produced a higher attitude mean score in the post-test. This appreciably lager experimental group's gain in the mean attitude score, might be an indication of the Ethnophysics - Based Instruction's ability to create and strengthen the attitude towards Density, Forces and Heat Transfer in college physics.

Research Question 3: What is the statistical difference in mean attitude scores between male and female students taught Density, Forces and Heat Transfer using Ethnophysics-Based Instruction? 
Table 6: Pre-Test Comparison of means and standard deviations of attitude scores between male and female students in experimental group $(n=71)$.

GENDER N Mean Std. Deviation Std. Error Mean

\begin{tabular}{llcccc}
\hline $\begin{array}{l}\text { Pre-test scores on } \\
\text { Attitude by } \\
\text { gender }\end{array}$ & Male students & 40 & 25.40 & 4.82 & 0.76 \\
& Female students 31 & 24.03 & 5.03 & 0.90 \\
\hline
\end{tabular}

Table 7: Post-test Comparison of means and standard deviations of attitude scores between male and female students in experimental group $(n=71)$.

\section{GENDER N Mean Std. Deviation Std. Error Mean}

\begin{tabular}{llllll}
\hline $\begin{array}{l}\text { Post-test scores } \\
\text { on Attitude by } \\
\text { gender }\end{array}$ & Male students & 40 & 40.18 & 4.60 & 0.73 \\
& Female students 31 & 40.87 & 3.88 & 0.70 \\
\hline
\end{tabular}

Results in table 11 and table 12 show that males had means of $25.40(\mathrm{SD}=4.82)$ and $40.18(\mathrm{SD}=4.60)$ in pre-test and post-test respectively. The gain was 14.78. For females, means stood at $24.03(\mathrm{SD}=5.030)$ in the pre-test and $40.87(\mathrm{SD}=3.88)$ in the post-test with a gain of 16.84 . Both the larger gain and small standard deviation for the female students indicate that Ethnophysics - Based Instruction had a greater effect on their attitude towards Density, Forces and Heat Transfer in College Physics.

Testing Null Hypotheses

The null hypothesis $1\left(\mathrm{Ho}_{1}\right)$, sought to find out if the was statistically significant difference in the mean academic performance of students taught Density, Forces and Heat Transfer using Ethnophysics - Based Instruction and those taught the same topics using Conventional Method. The null hypothesis 1 is thus stated as below.

Ho1: There is no statistically significant difference in academic performance mean scores between students taught Density, Forces and Heat Transfer using Ethnophysics-Based Instruction and those taught using conventional method. To test this null hypothesis, the post-test scores of the achievement test were subjected to two - sample independent $\mathrm{t}$ - test. The result is shown in table 13 .

Table 8: Independent t-test for post-test scores in the Achievement Test for the experimental group and control group $(n=156)$

\begin{tabular}{|c|c|c|c|c|c|c|c|c|c|c|c|}
\hline & \multirow[b]{2}{*}{ GROUPS } & \multirow[b]{2}{*}{$\mathrm{N}$} & \multicolumn{9}{|c|}{ Levene's } \\
\hline & & & Mean & Std. Deviation & Std. Error Mean & F & Sig & df & $t$ - value & $\mathrm{p}$ - value & Remark \\
\hline & Experimental & 71 & 21.42 & 3.53 & 0.42 & & & & & & \\
\hline $\begin{array}{l}\text { Post-test scores } \\
\text { for Achievement }\end{array}$ & & & & & & 0.71 & 0.40 & 154 & 6.06 & 0.00 & Significant \\
\hline Test & Control & 85 & 18.14 & 3.23 & 0.35 & & & & & & \\
\hline
\end{tabular}

Significant at alpha $=0.05$.

From table 13 , the calculated $\mathrm{t}_{(154)}=6.06 ; \mathrm{p}<0.05$. with this result is significant at alpha $=0.05$, the null hypothesis that there is no statistically significant difference in academic performance mean scores between students taught Density, Forces and Heat Transfer using Ethnophysics-Based Instruction and those taught the same topics using Conventional method is rejected and conclude that the alternative hypothesis that there is a statistically significant difference in academic performance mean scores between students taught Density, Forces and Heat Transfer using Ethnophysics-Based Instruction and those taught the same topics using conventional method is supported. This result shows that Ethnophysics - Based Instruction had a greater positive effect on students' academic performance in the experimental group than in the control group. To determine the magnitude 
of the effect, effect size was calculated using Cohen's d. The value of Cohen's $d=0.97$ was calculated from the formula:

$$
d=\frac{\bar{X}_{1}-\bar{X}_{2}}{S}
$$

Where $\bar{X}_{1}$ is mean for experimental group and $\bar{X}_{2}$ is the mean for control group and s is pooled standard deviation given by:

$$
s=\sqrt{\frac{s_{1}^{2}+s_{2}^{2}}{2}}
$$

Where $s_{1}$ is standard deviation of the experimental group and $s_{2}$ is standard deviation of the control group. According to Cohen (1988), a value of 0.50 and above is considered as large effect. This implies that Cohen's d $=0.97$ indicates that Ethnophysics - Based Instruction produced a very large positive effect in the academic performance of students in this study.

Null hypothesis $2\left(\mathrm{H}_{02}\right)$ was tested using independent t-test. The hypothesis is:

Ho2: There is no statistically significant difference in the mean attitude scores between students taught Density, Forces and Heat Transfer using Ethnophysics-Based Instruction and those taught the same topics using Conventional method. Table 14 shows summary of the test.

Table 9: Independent t-test for post-test attitude mean scores for the experimental group and control

\begin{tabular}{|c|c|c|c|c|c|c|c|c|c|c|c|}
\hline & \multirow[b]{2}{*}{ GROUPS } & \multirow[b]{2}{*}{$\mathbf{N}$} & \multicolumn{9}{|c|}{ Levene's } \\
\hline & & & Mean & Std. Deviation & Std. Error Mean & $F$ & Sig & df & $t$ - value & $\mathrm{p}$ - value & Remark \\
\hline & Experimental & 71 & 40.48 & 4.29 & 0.51 & & & & & & \\
\hline \multirow[t]{2}{*}{$\begin{array}{l}\text { Post-test scores } \\
\text { for Attitude }\end{array}$} & & & & & & 1.42 & 0.24 & 154 & 7.49 & 0.00 & Significant \\
\hline & Control & 85 & 34.96 & 4.81 & 0.52 & & & & & & \\
\hline
\end{tabular}
group $(\mathbf{n}=156)$.

Significant at alpha $=0.05$.

The results from table 14 reveal that $\mathrm{t}_{(154)}=7.49 ; \mathrm{p}<0.05$. We therefore reject the null hypothesis that there is no statistically significant difference in the mean attitude scores between students taught Density, Forces and Heat Transfer using Ethnophysics-Based Instruction and those taught the same topics using Conventional method and conclude that the alternative hypothesis that there statistically significant difference in the mean attitude scores between students taught Density, Forces and Heat Transfer using Ethnophysics-Based Instruction and those taught using Conventional method is true and tenable at alpha $=0.05$ in favor of the experimental group. The effect size of 1.21 was calculated using the formula:

$$
d=\frac{\bar{X}_{1}-\bar{X}_{2}}{S}
$$

This value for effect size is large according to Cohen (1988). This means that Ethnophysics - Based Instruction has the potential to re-shape students' attitude towards Density, Forces and Heat Transfer in College Physics. Therefore, this effect cannot be ignored.

The null hypothesis $3\left(\mathrm{H}_{03}\right)$ sought to find out if there is a statistically significant difference in mean attitude scores between male and female students taught Density, Forces and Heat Transfer using Ethnophysics-Based Instruction. Thus it states;

$\mathbf{H}_{\mathbf{0}}$ : There is no statistically significant difference in mean attitude scores between male and female students taught Density, Forces and Heat Transfer using Ethnophysics-Based Instruction. Table 15 presents the result of the test for null hypothesis 3 .

Table 10: Independent t-test for post-test attitude scores for male and female students in the experimental $\operatorname{group}(\mathbf{n}=71)$.

\begin{tabular}{llllllllllll}
\hline & GENDER & N & Mean & Std. Deviation & Std. Error Mean & F & Sig & df & t - value & p - value & Remark \\
\hline $\begin{array}{l}\text { Post-test scores } \\
\text { on Attitude by } \\
\text { gender }\end{array}$ & Male students & 40 & 40.18 & 4.60 & 0.73 & & & & & & \\
& & & & & & 0.74 & 0.39 & 69 & -0.68 & 0.50 & Non-Significant \\
& Female students 31 & 40.87 & 3.88 & 0.70 & & & & & & & \\
\hline
\end{tabular}

Significant at alpha $=0.05$.

Results in table 15 show that $\mathrm{t}_{(69)}=-0.68 ; \mathrm{p}>0.05$. Basing on results of table 15 , we fail to reject the null hypothesis that there is no statistically significant difference in mean attitude scores between male and female 
students taught Density, Forces and Heat Transfer using Ethnophysics-Based Instruction and conclude that the alternative hypothesis that there is a statistically significant difference in mean attitude scores between male and female students taught Density, Forces and Heat Transfer using Ethnophysics-Based Instruction is not tenable. This means that Ethnophysics - Based Instruction is not gender biased. The following are the main findings of this study:

1. Students taught Density, Forces and Heat Transfer using Ethnophysics - Based Instruction performed better than those taught the same topics using Conventional method.

2. Ethnophysics - Based Instruction (EBI) had a statistical significance on academic performance

3. Ethnophysics - Based Instruction (EBI) had large effect size on the academic performance of students.

4. Ethnophysics - Based Instruction (EBI) had statistical significance on attitude towards Density, Forces and Heat Transfer in College Physics

5. Ethnophysics - Based Instruction (EBI) had large effect size on the attitude of students towards Density, Forces and Heat Transfer in College Physics

6. Students taught Density, Forces and Heat Transfer using Ethnophysics - Based Instruction (EBI) developed a larger mean positive attitude score than those taught the same topics using Conventional method.

7. Ethnophysics - Based Instruction (EBI) is not gender biased.

\section{Discussion of the Results}

The results from testing the null hypothesis one showed that the participants in the experimental group who were taught density, forces and heat transfer using ethnophysics - based instruction performed significantly better than their counterparts in control group who were taught the same topics using conventional method. Effect size of 0.97 as Cohen's d, implies large effect produced by EthnoPhysics -Based Instruction (EBI) on the performance of the participants in the experimental group. These results show the effectiveness of ethnophysics - based instruction in enhancing students' academic performance over conventional method. This could be because ethnophysics - based instruction used events, practices, artefacts and ideas which were very familiar to students. Figures 1 to 3 show some of the home practices which were used in EBI.

(Figure 1): Carrying containers of water in both hands (a), Carrying in one hand and children playing a game called "Sojo" (c).

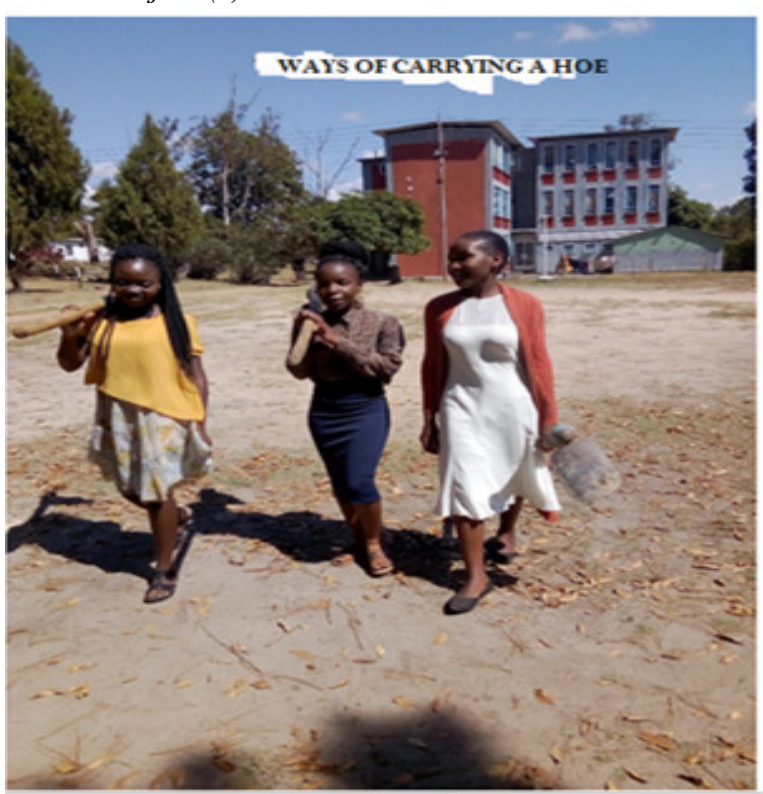

a. Carrying hoes

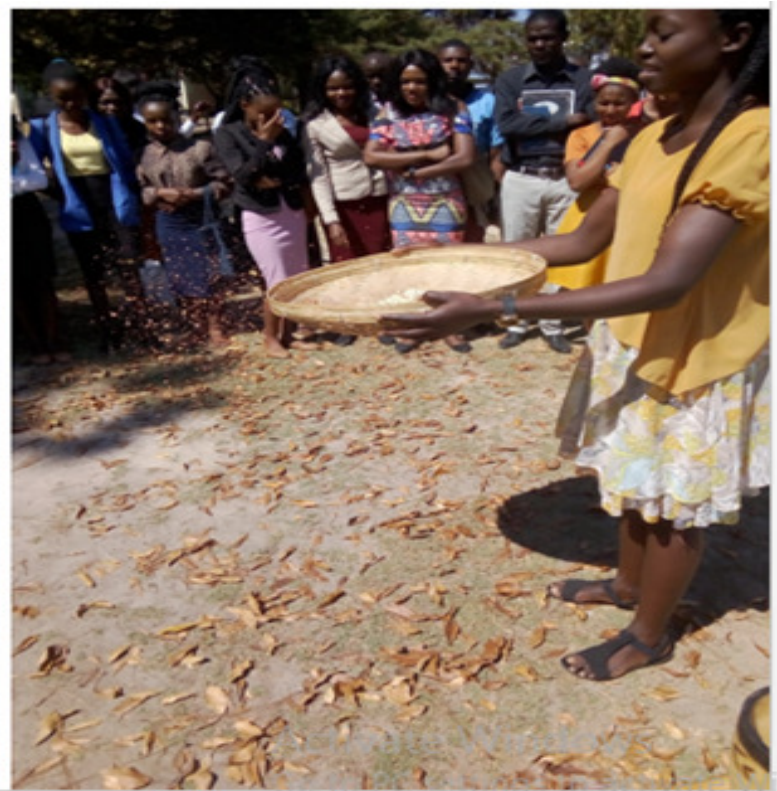

b. Type of winnowing

(Figure 2): Carrying hoes (a) and one type of winnowing (b) 

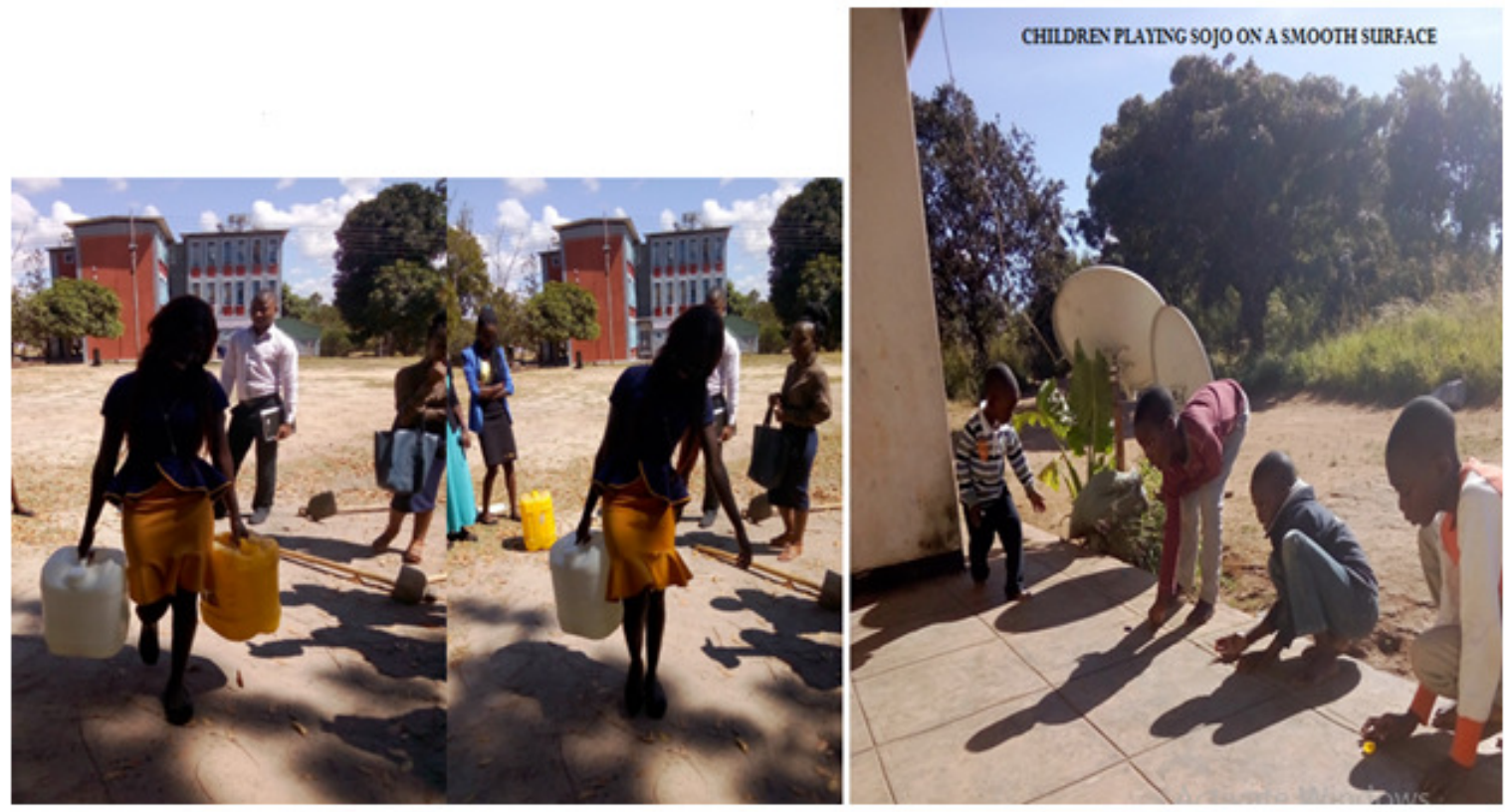

a. Carrying on both hands b. Carrying in one hand c. Playing a game "sojo"
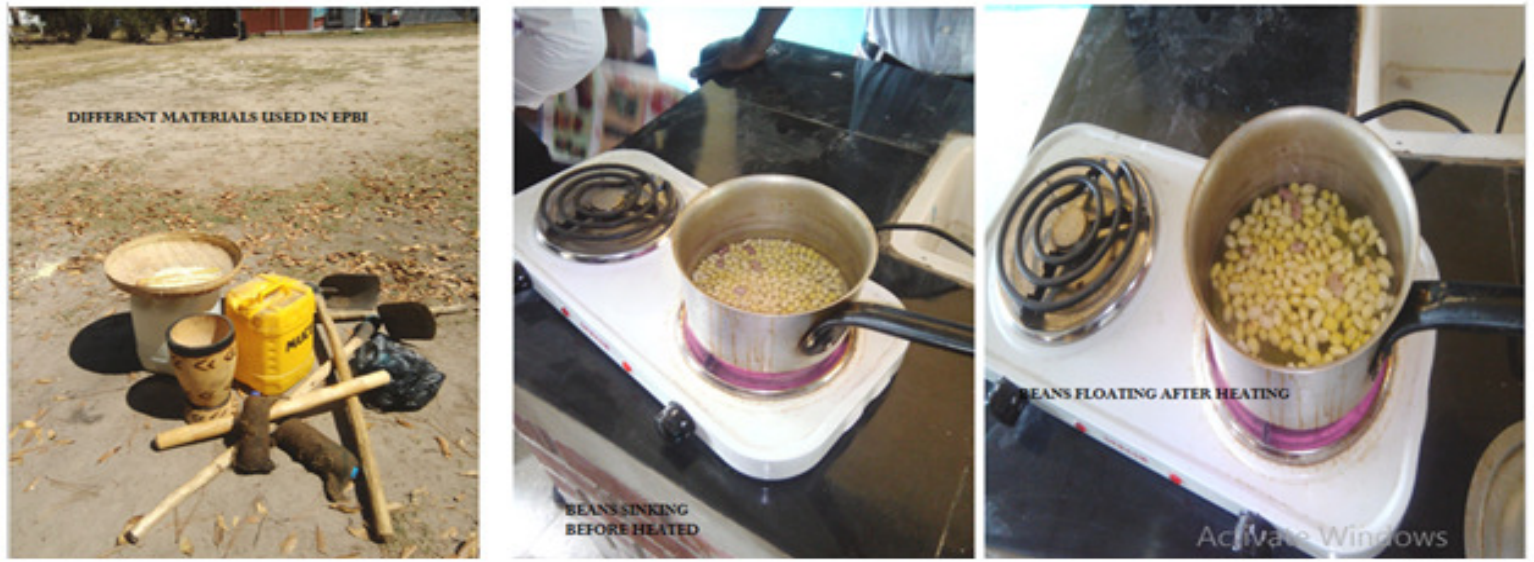

a. Items used

b. Beans sinking before heating c. Beans floats after heating

(Figure 3): Items used in EBI (a), beans sinking before heating (b) and beans floating after heating (c).

The finding of this study is supported by those of Achor, Imoko, \& Uloko (2009) who studied the effects of Ethnomathematics Teaching Approach (ETA) on senior secondary students ${ }^{\text {ee }}$ performance and retention in locus. Their findings revealed that students taught Locus using ETA had higher academic performance than those taught using the conventional approach. They argued that the higher performance by the ETA taught group was because the group was able to integrate or link their background/indigenous knowledge to the new concepts they were taught. The finding is also in line with those of Peni (2015) who studied the impact of EthnoscienceEnriched - instruction on attitude, Retention and performance in Basic Science among Rural and Urban students in Kano State, Nigeria. His study showed that the subjects in the experimental groups taught Basic Science concepts using the ethnoscience-enriched-instruction performed significantly better than their counterparts in the control group who were taught same concepts using lecture method. The finding of this study is against Solomon's (1993) assertion that Science (Physics inclusive) should be taught in laboratories. This study has revealed that it is the approach which might matter most and not merely the place.

The null hypothesis two sought the effect of ethnophysics - based instruction on students' attitude towards density, forces and heat transfer in college Physics in experimental and control groups. Post-test results in table 7 have indicated that experimental group had a more relative positive attitude than the control group. The difference in the attitude towards density, forces and heat transfer in college Physics among students exposed to ethnophysics- based instruction and those exposed to conventional method was statistically significant with a 
large effect size of 1.21. This effect observed could be attributed to the students' familiarity with the practices used in experimental group. Learning was funny and enjoyable with a known lived experience and relevance attached to the activities of the experimental group. Students had smiles on their faces and at times they looked surprised to find how scientifically rich the simple practices in their homes were. Some students could not hold back their appreciation of the instructional approach used by writing on the questionnaire how grateful they were even when they were not asked to do so. The other surprising thing was that students were available even when it was an arranged time of meeting them. These findings in this study could be pointing out that EthnoPhysics Based Instruction (EBI) has an inherent potential to create, change and improve the attitude of students towards density, forces and heat transfer in college Physics. It could be true that cultural practices are held with high esteem by students. As such, a teaching that recognizes way of life of learners rekindles, creates and re-orients attitude. The effect of ethnophysics - based instruction on students' attitude towards the selected topics in college Physics found in this study is in line with Nashon and Anderson (2013) who found that contextualized teaching made learners form positive attitudes towards Science. This study further confirms what Dana (2006) observed that a person's attitude is learned not inherited and that such attitudes can be influenced through effective instructional strategies. It also agreed with the positions of Cracker (2006) and Akinbobola \& Ikitde (2008) who established that a person's attitudes are learned; as opposed to being inherited thus it can be changed through persuasion using a variety of techniques.

Null hypothesis three sought to find out if there was significant difference in attitudes between male and female students taught density, forces and heat transfer using ethnophysics - based instruction. Table 12 indicates that there was no statistically significant difference in attitude of male and female students and small effect size of 0.16 was obtained. This result could stem from the balance which was there in the treatment. Some activities like playing of a game called 'sojo' and carrying logs are done mainly by males in the community while carrying objects on the head without holding and cooking beans lean more to females' activities. Winnowing and carrying hoes are done by both males and females. In this sense, there was no biasness in the practices used in the experimental group. However, the mean of female students was higher than that of male students. The standard deviations also revealed that female students' attitude was nearer the mean as it was smaller than that of male students. This is in line with both Peni (2015) who found that students' attitude based on gender revealed a significant difference in favor of the female students and Abonyi (2002) who established that although, the mean score of students interest to science between male and female was not statistically different, female students had relatively higher mean compared to males students. This finding shows that ethnophysics - based instruction does not favour only male students but rekindles female students' attitude towards density, forces and heat transfer in college Physics as well. The result of this study resonates very well with Peni's (2015) study that the use of culturally relevant practices that are familiar to the female students enhanced their attitude towards the study of Science. Generally, this study agrees with the studies of Abonyi (2014) and Savelsbergh's et al (2016) that ethnophysics provides three irreplaceable benefits: Firstly, it is a base for construction of reality by learners; secondly, it acts a bridge through which learners from various backgrounds cross over to modern conventional or western physics and thirdly, this approach clears false beliefs about physics. Therefore, teaching Physics using conventional method is like revising known concepts in an unfamiliar language such that known materials sound completely new. Adesoji (2008) and Guido (2013) have established that a significant relationship exists between attitude and method of instruction and also between attitude and performance and it is possible to predict performance from attitude scores.

\section{Conclusion}

This study sought the effect of ethnophysics - based instruction on students' academic performance and attitude towards density, forces and heat transfer in college physics at Mufulira College of Education. It was concluded that the instructional approaches used in teaching density, forces and heat transfer significantly affected the academic performance of students in the achievement test on the stated topics. The experimental group performed better than their counterparts in the control group. This enhanced academic performance was attributed to ethnophysics - based instruction used in the experimental group and the relative poor academic performance in the control group was attributed to the conventional method used to teach that group. EBI was found to be gender friendly as the attitude of both male and female students exposed to it was equally positively affected and that its instructional activities were evenly distributed in Zambian homes thereby providing equal attitudinal favour to both male and female students. The study also established that ethnophysics (home practices) do not create conflict in the students' knowledge systems on density, forces and heat transfer. This means that Zambian home practices have a complimentary relationship with density, forces and heat transfer in college physics.

\section{References}

1. Abonyi, S.O., Achimugu, L. \& Adibe, M.I. (2014). Innovation in Science and Technology Education: A 
Case for Ethnoscience Based Science Classrooms. International Journal of Scientific \& Engineering Research, 5(1):52

2. Adams, H. (1983). African Observers of the Universe: The Sirus Questions in I.V Sertima (Ed) Blacks in Science: Ancient and Modern. New Brunswick Transition Books.

3. Adesoji, F.A. (2008). Managing Students' Attitude towards Science through Problem-solving Instructional Strategy. Anthropologist, 10(1):21-24

4. Akinbobola A. O. \& Ikitde, G. A. (2008). Facilitating Students Attitude in the Concept of Heat Energy in Nigerian Secondary School Physics Using Models, Realia and Instructional Charts. African Research Review, 2 (2). 56-68

5. Ausubel, D. P. (1972). In Defense of Advance Organizers: A Reply to the Critics. Review of Educational Research, 48: 251-257

6. Craker, D. E. (2006). Attitudes Towards Science of Students Enrolled in Introductory Level Science Courses at UW-La Crosse. UW-L Journal of Undergraduate Research, IX.

7. Gail, M. S. \& Anthony, R. A. Jr. (2013). Analysing and Interpreting Data from Likert - Type Scales. Journal of Medical Education, 5(4): 541 - 542. DOI:htt://dx.doi.org/10.4300/JGME-5-4-18

8. Guido,R.M.D. (2013). Attitude and Motivation towards Learning Physics. International Journal of Engineering \& Technology,2(11):2087.

9. Halubova, R. (2008). Effective Teaching Methods-Project-Based Learning in Physics. US-Education Review, 5(12):27.

10. Harry, N. B. Jr. \& Deborah, A. B. (2012). Analysing Likert data. Journal of Extension, 50(2)

11. Haskell,R. (2001). Transfer of Learning: Cognition, Instruction and Reasoning Educational Psychology Series, Academic Press.

12. Heckenberger, M.J. (2005). The Ecology and Power: Culture, Place and Personhood in the Southern Amazon. New York: NY, Routledge:303.

13. Ibe, E., \& Nwosu, A. A. (2017). Effects of Ethnoscience Traditional Laboratory Practical on Science Process and Skills Acquisition of Secondary School Biology Students in Nigeria. British Journal of Multidisciplinary and Advanced Studies, 1(1):35-46.

14. Kiptum, M.G. (2015). Difficulty Physics topics in Kenyan secondary schools: A case study of Uashin Gishu County. Scholarly Journal of Education,4(4)

15. Kola, J.A. (2014). Student Learning of Physics in Colleges of education: Analysis of Performance. International Journal of DevelopmentResearch,4(11).2409

16. Lawrence, B.A. (2017). The Integration of ethnophysics into school Curriculum for Skill Acquisition among Secondary School Students in Nigeria. International Journal of Innovative Research and Advanced Studies, 4(8): $62-64$

17. Maguswi, B.V. (2011). Factors Contributing to Underachievement of Zambian Female students in O- level Physics Examinations. A case of selected high schools in central Province.

18. Malcom, C. (2001). When Cultures Meet. University of Durban-Westville. Durban

19. Masingila, J. O. (1993). Learning from Mathematics Practice in Out - of - School Situations. For the Learning of Mathematics, 13(2):19-22

20. Michie, M. (1999). "Reforming Learning, Curriculum and Pedagogy: Innovative Visions for the New Century”, Paper Presented at the Fifth UNESCO-ACEID International Conference Bangkok, Thailand.

21. Ministry of National Development Planning, (2017). Seventh National development Plan 2017-202, Lusaka-Zambia

22. MoGE in Focus, (2017). A Ministry of General Education Bulletin (1):28

23. Naidoo, P. D. (2010). Teachers' Interpretation and Implementation of the Policy on Indigenous Knowledge in the Science National Curriculum Statement, University of Kwa-Zulu Natal, South Africa.

24. Nashon, S. M., \& Anderson, D. (2013). Interpreting student views of Learning Experiences in a Contextualized Science Discourse in Kenya. Journal of Research in Science Teaching, 50(4):381-407

25. Novika, L.\& Fajar, F. (2016). Physics Education based ethnoscience: Literature Review. International Conference on Mathematics, Science and Education: 30

26. Ogunkola, B. J. and Samuel, D. (2011). Science Teachers ${ }^{e e}$ and Students ${ }^{e e}$ Perceived Difficult Topics in the Integrated Science Curriculum of Lower Secondary Schools in Barbados. World Journal of Education, 1 (2) retrieved from www.sciedu.ca/wje on 24/4/2014. doi:10.5430/wje.v1n2p17

27. Peni, H. Y. (2015). Impact of Ethnoscience-enriched Instruction on Attitudes, Retention and Performance in Basic Science among Rural and Urban students in Kano state, Nigeria.pp 1-220 
28. Savelsbergh, E. R. et al. (2016). Effects of Innovative Science and Mathematics Teaching on Student Attitudes and Achievement: A Mata-analytic Study. Educational Research Review, 19(2016):158-172

29. Shumba, O. (2017). Tackling Educational Quality and Epistemological Access Concerns in Science and Technology Education in Africa: The "Learning - as - Connection" Perspective. African Perspectives of Research in Teaching and Learning, 1(1):18

30. Solomon, J. (1993). Teaching Science, Technology and Society, Open University Press, 1993. ISBN, 0335099521

31. Ugwu A. N., \& Diovu, C. I. (2016). Integration of indigenous Knowledge and Practices into Chemistry Teaching and Students' Academic Achievement. International Journal of Academic Research and Reflection, 4(4):1-12

\section{Declaration and Certification}

I, Ephraim Chongo, do hereby declare that this dissertation entitled, "Effect of EthnoPhysics - Based Instruction on Students' Academic Performance and Attitude towards Density, Forces and Heat Transfer in College Physics: A Case of Mufulira College of Education" was conducted and written by me as a record of my own research work and work of other persons utilised in this dissertation has been duly acknowledged accordingly. This dissertation is being submitted for the award of the degree of Master of Science in Physics Education of the Copperbelt University, School of Graduate Studies. It has not been submitted before for any degree or examination at any other university.

\section{Acknowledgements}

First and fuller acknowledgement is directed to the Almighty God for his Mercies and Blessings he has bestowed on me.

I wish to acknowledge the profound contributions made by my research supervisor Mr. Baliga T. G., HOD Physics section, Copperbelt University for his guidance throughout the research project.

Other special acknowledgements for the contributions to this research project go to Mr. Chileshe, L., Principal - Mufulira College of Education, Mr. Chirwa, P., Mathematics lecturer - St. Marys' College of Education, Mr. Chipowe, P., Mathematics lecturer - Malcom Moffat College of Education, Mr. Chongo, B., lecturer - Apex University, Prof. Shumba, O., - Copperbelt University, Rev. Fr. Tambatamba, A. B., SESO Lusaka Province and Ms. Mwendabai, B., Biology lecturer - St. Marys' College of Education.

I further recognize Mr. Kwenge, E., Vice Principal - St. Marys' College of Education, Mr. Nkwale, B., Vice principal Malcom Moffat College of Education, Mr. Mubanga, L., HOD Natural Sciences Department - St. Marys' College of Education, Mr. Chanda, P., Chemistry lecturer - St. Marys' College of Education, Mr. Chileshe, E., Chemistry lecturer - St. Marys' College of Education, Mr. M'sikita, M., Physics lecturer - Mufulira College of Education, Mr. Tebeka, J., HOD Natural Sciences Department - Mufulira College of Education, Mr. Chitoshi, Mathematics lecturer - Mufulira College of Education, Mr. Mvula, A. K., Physics lecturer - Mufulira College of Education, Mr. Musonda, D., Physics lecturer - Mufulira College of Education, Sr. Chanda, A., Kapatu Secondary School, Ms. Nalavwe, S., Lucheche Secondary School, Mr. Phiri, M. K. - Masaiti Boarding, Secondary School, Mr. Zimba, J., Mukobeko Secondary School, Mr. Kapampa, J., - Lukashya Trades Secondary School, Mr. Kalolo, A., Ms. Nyirenda, R., - St. Francis Secondary School, Mr. Mwaiba, M., Chemistry lecturer - Mufulira College of Education 